
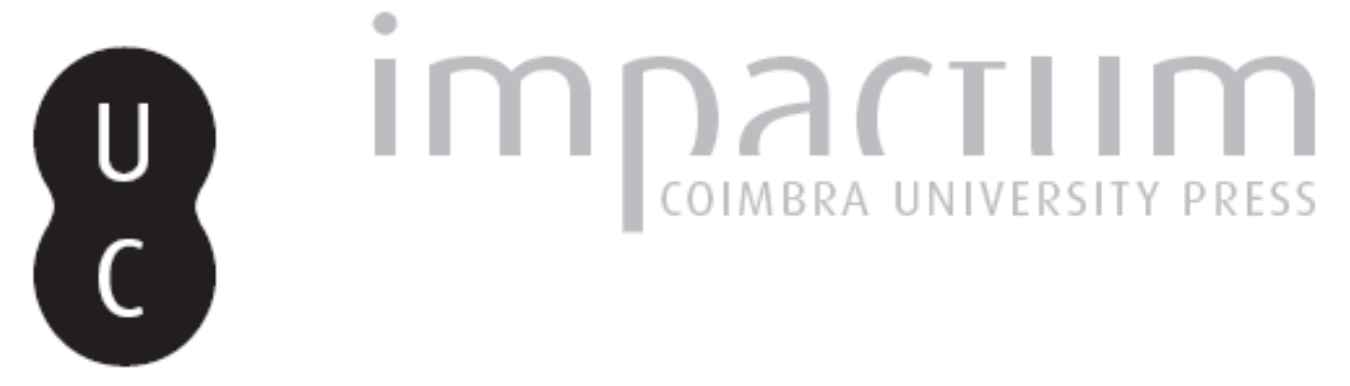

\title{
Absolutismo y liberalismo en el siglo XIX español
}

Autor(es): $\quad$ Gil Novales, Alberto

Publicado por: Imprensa da Universidade de Coimbra

URL persistente:

URl:http://hdl.handle.net/10316.2/45086

DOI:

DOI:https://doi.org/10.14195/2183-8925_7-2_14

Accessed : $\quad$ 26-Apr-2023 11:45:39

A navegação consulta e descarregamento dos títulos inseridos nas Bibliotecas Digitais UC Digitalis, UC Pombalina e UC Impactum, pressupõem a aceitação plena e sem reservas dos Termos e Condições de Uso destas Bibliotecas Digitais, disponíveis em https://digitalis.uc.pt/pt-pt/termos.

Conforme exposto nos referidos Termos e Condições de Uso, o descarregamento de títulos de acesso restrito requer uma licença válida de autorização devendo o utilizador aceder ao(s) documento(s) a partir de um endereço de IP da instituição detentora da supramencionada licença.

Ao utilizador é apenas permitido o descarregamento para uso pessoal, pelo que o emprego do(s) título(s) descarregado(s) para outro fim, designadamente comercial, carece de autorização do respetivo autor ou editor da obra.

Na medida em que todas as obras da UC Digitalis se encontram protegidas pelo Código do Direito de Autor e Direitos Conexos e demais legislação aplicável, toda a cópia, parcial ou total, deste documento, nos casos em que é legalmente admitida, deverá conter ou fazer-se acompanhar por este aviso.

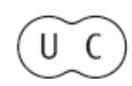




\section{REVISTA DE HISTORIA DAS IDEIAS 7}

\section{REVOLTAS E REVOLUCOẼS}

\section{**}

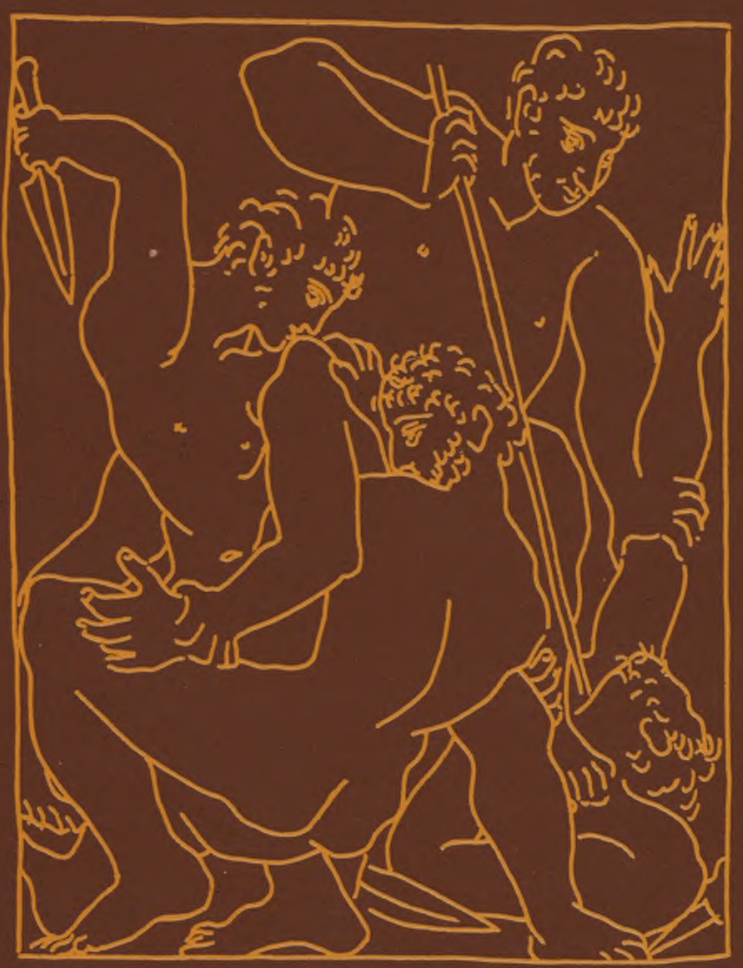

INSTITUTO DE HISTÓRIA E TEORIA DAS IDEIAS FACULDADE DE LETRAS 


\section{ABSOLUTISMO Y LIBERALISMO EN EL SIGLO XIX ESPAÑOL (*)**}

No pretendo en esta conferencia contar la historia alternativa de los períodos absolutistas y liberales en el siglo XIX español, historia por lo demás que tiene un esquema muy fácil: en 1808 con la invasión napoleónica desaparece la monarquía tradicional española, sustituida por una interinidad revolucionaria, en cuyo seno las Cortes de Cádiz promulgan en 1812 la primera Constitución. Destruida ésta dos años más tarde, a la vuelta de Fernando VII que ha estado prisionero en Francia, se inicia el primer período absolutista, 1814-1820. La revolución de este último año crea lo que tardíamente se llamó el Trienio Liberal, vigencia de la Constitución de Cádiz, que dura hasta 1823 . En esta fecha la nueva invasión francesa restablece el absolutismo, que se prolongará hasta 1833, hasta la muerte del rey. Mientras una parte de la población inicia en este año un intento de vuelta al absolutismo, que se repetirá dos veces más a lo largo del siglo - las guerras carlistas - y aun lanzará sus boinas rojas sobre la guerra civil de 1936-1939, la mayor parte del país vive bajo la Reina viuda María Cristina y bajo Isabel II, su hija, un sistema liberal o por lo menos constitucional, sin que en ningún momento ulterior se pueda decir que formalmente ha vuelto España a recaer en el absolutismo. A partir del llamado Estatuto Real de 1834 los diversos gobiernos que rigen España y las diversas revoluciones que la agitan, todos de manera más o menos intensa, con mayor o menor concesión de derechos al pueblo, reconocen una norma superior, una Constitución, a la

(*) Facultad de Ciencias de la Información de la Universidad Complutense de Madrid.

(**) Conferencia proferida na sessão de apresentação do n. ${ }^{\circ} 6$ da Revista de Historia das Ideias. 


\section{Varia}

que teoricamente se someten, aunque con frecuencia la modifican a sua manera.

Repito: lo que me interesa es algo más sutil que contar las alternancias. Quiero tratar de ver cómo el absolutismo se infiltra, por decirlo así, en el liberalismo, hasta desvirtuarlo totalmente y convertirlo en lo que los escolásticos llamaban «flatus vocis». Lo particular de esta curiosa evolución estriba en que a través de esta auténtica desustanciación España hace su revolución burguesa: antes de que empiece el proceso España es una Monarquía señorial o feudal; a su final es también una Monarquía, pero burguesa; aunque quedarán todavía muy persistentes algunos restos anacrónicos de feudalismo, entre los que no sé si colocar la existencia misma de la Monarquía. Hoy día en España todo se compra y se vende, valor supremo ante el que naufraga la misma idea de colectividad; pero no es infrecuente que el frenesí burgués se vea acompañado por añoranzas del pasado bárbaro, aristocrático e inquisitorial del país.

Esta es la evolución que quisiera presentar ante Vds. Algunos escritores, precisamente del sector más reaccionario de la actual historiografía española, han pretendido que España realizó su revolución burguesa durante el siglo XVIII, concretamente en la época de Carlos III (1759-1788), época de las grandes reformas interiores en que culmina la Ilustración nacional. Pero aunque pudiera entenderse que la Ilustración es burguesa porque prepara el terreno al triunfo de la burguesía, en España el crecimiento económico evidente en esta época no pone nunca en peligro los intereses monárquico-señoriales. Y en cierta manera el fracaso político de la Ilustración, visible en todos los países de Europa antes, bastante antes de la Revolución francesa, se da también en España, quizá anticipándose o por lo menos coetáneamente a los otros países europeos. Aún así España parece acabar la centuria dieciochesca en pie de igualdad, un escalón acaso más abajo, que países como Francia e Inglaterra. A este espejismo ha contribuido el hecho de que bajo Carlos IV (1789-1808) España se vea cada vez más abocada a guerras contra Inglaterra, pero que sea Inglaterra precisamente el país que proporciona cañones a nuestra Marina - lo cual resulta una dependencia extremadamente irritante - prolonga la Ilustración y la actividad científica sobre todo en América, hasta que los primeros movimientos de independencia la clausuran definitivamente, porque las autoridades españolas en América aplican el viejo principio de que el pensamiento delinque.

Pero hay que tener en cuenta también que la creación dieciochesca de riqueza, el superavit económico de la centuria, no se gasta en obras reproductivas, en acumulación de capital industrial, sino mayoritariamente en obras de ornato, que si 
hoy dan cierta belleza a tantos lugares recónditos del país, representa económicamente hablando una disipación. En estas condiciones para realizar su revolución industrial en el cruce entre los dos siglos, España tendría en el XIX que haber conservado las colonias americanas, a fin de saquearlas en beneficio de la metrópoli; o tendría que haber conservado por lo menos la propia riqueza material peninsular acumulada en los tiempos anteriores: la guerra de la independencia (1808-1814), terriblemente destructora, la inestabilidad política subsiguiente, y la guerra civil carlista (1833-1840) se encargaron de destruir esa riqueza, empobreciendo al país hasta límites insospechados.

No obstante, la guerra de 1808 y la independencia de América serían explicaciones demasiado cómodas. La verdad es que muchas de las empresas españolas aparentemente más florecientes en el siglo XVIII se hallan ya en crisis o fracasadas antes de que termine la centuria, indicando carencias que muy caro le van a costar al país. El ímpetu dieciochesco desaparece consumido en sí mismo, antes de que factores como la independencia de América y la invasión napoleónica vengan a privarla de sus esperanzas de gran potencia.

Porque España no lo es. Yo no diré, como decía Ortega y en cierta manera ha repetido el historiador conservador británico Kamen, que la Historia de España es la Historia de una decadencia; diré solamente que en el siglo XVIII los capitalismos que se adelantan al español, fundamentalmente el inglés y el francés entre sí enemigos, viven al acecho de arrebatar a España las inmensas riquezas americanas, cosa que logrará Inglaterra con la emancipación de las colonias. Ambos capitalismos ahogan y deprimen al español.

Por razones internas y externas no quedará de la Ilustración más que la memoria de las buenas intenciones. Me interesa destacar que el liberalismo tratará de completar lo que la Ilustración dejó incompleto, y que a las debilidades de la Ilustración en su época clásica corresponden las debilidades del liberalismo en la suya; aunque también es justo decir que el liberalismo representa la culminación de la Ilustración, es decir, la aportación al acervo español de los temas y modos que faltaron en el siglo ilustrado, lo mismo que a través del liberalismo de 1820 sentimos como una recuperación de herencias que la historia pasada nos negó, por ejemplo la experiencia europea de la reforma protestante.

Un rasgo fundamental del significado de la Ilustración española y de su alcance real lo tenemos en el tratamiento dado a la Mesta, la poderosa corporación de ganaderos, responsable de la despoblación y la miseria de muchas regiones españolas. No hay duda de la seriedad y categoría de los propósitos 
de reforma emprendidos por el equipo gobernante de Carlos III, en torno al conde de Campomanes; tampoco la hay sobre el carácter de las espléndidas colecciones de documentos que con este propósito se escribieron o se reunieron. En cambio la legislación de reforma antifeudal introducida no pasa de ser discretamente moderada y poco efectiva; pero un donativo hecho por la Mesta en 1797, ya bajo Carlos IV, terminó con la existencia incluso de esa tímida legislación. Fracaso absoluto, aunque como siempre para tiempos futuros nos quedó el testimonio.

En estas condiciones la revolución española no puede ser muy profunda - y digo esto aun a sabiendas de que sí es profundo el cambio del feudalismo al dominio burgués absoluto. Acaso expresándome mejor, se trata de la forma en que se vivió esa revolución, dilatada a lo largo del tiempo.

La desaparición del Antiguo Régimen en España, aunque ya anunciada quizás por los famosos motines de 1766, tuvo lugar por acción ajena: la invasión napoleónica, ante la cual se humilla hasta límites que hoy nos parecen mentira la vieja monarquía. Pero esa fecha da lugar también a la reacción popular, al instinto soberbio de defensa del pueblo, más o menos canalizado por la Iglesia en un sentido reaccionario de guerra patriótica, fenómeno que ya, fuera de nuestras fronteras, había aparecido en Francia en la Guerra de los Siete años (1756-1763), cuando los sectores reaccionarios del país trataron de aprovechar la emoción patriótica para identificarla con la condena de las ideas ilustradas.

En Francia el intento reaccionario fracasó; en España, no tanto; aunque por si acaso, en la evolución política del país insurreccionado contra la ocupación francesa surgieron nuevos mitos, siempre ligados a lo patriótico, que sólo ahora quizá estemos en condiciones de poder ver y analizar. Surge el mito del rey víctima, del rey esperado, ante el que todos se inclinan, aun a sabiendas de que Fernando es un felón que desde Valencey felicita a los franceses por sus triunfos militares en España. Pero es que, aunque Fernando sea malo, la monarquía es necesaria como contención social, lo mismo que la misma religión, para estar seguros de que la revolución no llevará a un desbordamiento popular - o digámoslo en términos franceses, a un jacobinismo.

El hecho precisamente de que la revolución francesa de 1789 sea anterior a la española, esto que parece una boutade, alcanza gran significación porque por ello mismo los liberales españoles tendrán siempre miedo del pueblo, miedo en potencia, y harán su revolución a espaldas del pueblo, y con frecuencia contra él. La misma formación de Juntas, que ha parecido siempre creación espontánea del genio nacional, si por 


\section{Absolutismo y Liberalismo}

una parte obedece a la necesidad, local o regional, de coordinar las acciones de la guerra contra el invasor, por otra obedece al propósito temprano de someter al pueblo, de darle la solución política antes de que el pueblo pueda intentar cualquier otro tipo de organización.

Las Juntas, no obstante, son por su origen órgano revolucionario; y cuando la misma dinámica de su existencia las lleva a crear con delegados de todas la Junta Central, surge un tipo de militar, como Gregorio Cuesta, que no comprendiendo nada de lo que pasa y creyendo de origen divino su nombramiento de Capitán General, adelanta el primer pronunciamiento al detener a los delegados de la Junta de León, que van a la Central. Tampoco esto logró evitar la formación de la Central, pero quedó como una premonición de lo que una parte del Ejército podía significar.

Las Juntas son una especie de alguacil alguacilado: si han nacido, so pretexto de patriotismo, para vigilar al pueblo, la Junta Central, a su vez, las vigila y las elimina, no fiándose del impulso popular que a través de ellas pese a todo pueda persistir. El progreso político vendrá del clamor nacional producido por las derrotas, del miedo a desaparecer, y también de la necesidad de crear una organización política estable, que modernice el Estado - y la modernización sólo puede tener sentido burgués - y evite en el futuro la repetición de situaciones como la que, con Godoy, ha hecho posible la invasión extranjera.

Así nacen las Cortes de Cádiz, 1810, ciudad libre de franceses y de ingleses, esto es fundamental, que reconocen lo que ya estaba en la calle: la libertad de expresión, por primera vez en la historia de España, que dan el decreto de abolición de los señoríos, 1811, que promulgan la famosa Constitución de 1812, y suprimen el odiado Tribunal de la Inquisición, 1813. No hay duda de que en lo legislativo la revolución española ha avanzado mucho con estas medidas.

Pero muy pronto empezará la preocupación por regular la libertad de expresión, lo cual equivaldrá en la medida de lo posible a eliminarla. La abolición de los señoríos, medida eminentemente popular, encuentra la resistencia lógica de los señores, a los que se permite conservar las tierras que tengan en pleno dominio, ya que la abolición no es una medida, o no quiere ser, que atente contra la propriedad. Los señores deberán presentar los títulos de propiedad. Entre la guerra y la resistencia de los interessados, no hay tiempo para llevar a la práctica el decreto, que queda postergado para más adelante. La Constitución de 1812, unicameral, necesita una serie de leyes complementarias y de reglamentos que incorporen sus principios a la realidad práctica del país. No habrá tiempo, medios o 
posibilidad de hacerlo entre 1812 y 1814 . Aun así, la Constitución se ha hecho, inspirándose en la francesa de 1791, para un pueblo en lucha, y contiene por ello mismo algunos elementos democráticos: igualdad de todos ante la ley, aunque habrá ciudadanos de segunda - fundamentalmente los de origen africano; igualdad impositiva - aquí igualdad implica proporcionalidad; desaparición de las prisiones y las muertes arbitrarias. Y aquel famoso artículo 2, bandera revolucionaria para tiempos posteriores, en España y en países tan distantes como Rusia y la República Dominicana: «La Nación española es libre e independiente, y no es ni puede ser patrimonio de ninguna persona ni familia». Pero junto a estos elementos progresistas, era una Constitución confesional, católica, y monárquica, que si bien establecía que el rey constitucional no podía dar órdenes sin la firma de un ministro responsable, daba a ese mismo rey el mando supremo de las fuerzas armadas, y la potestad de nombrar y quitar libremente a los ministros. Además, en el Preámbulo a la Constitución - anónimo, pero obra de Argüelles - se establecía que la Constitución no podría ser revisada hasta pasados ocho años, es decir hasta 1820 - época en que se calculaba que habría terminado ya la guerra contra Napoleón - y entre líneas se advertía que en ese año se procedería a revisar la Constitución en un sentido censitário, oligárquico.

El decreto de abolición de la Inquisición, ya anticipado por el rey Intruso en 1809, se vio favorecido por una minoría del clero ilustrado, pero rechazado por la Iglesia en general.

Pero cuando en 1814 Fernando VII dio su famoso decreto de Valencia, por el que se abolía toda la labor de las Cortes de Cádiz y se declaraba reos de Estado a los liberales, todo pareció volver a la situación anterior. Otra vez censura, catolicismo de contrareforma, monarquía absoluta, régimen señorial, Inquisición.

Sorprende la impreparación liberal ante el golpe de Estado de Fernando VII, con el que lejos de volver al régimen esclarecido de sus mayores, inicia una dictadura moderna. Fernando VII se había basado para su golpe en una parte del Ejército, el que mandaba el general Elío, es decir un general con experiencia de sedición americana, ya que había sido gobernador militar de Montevideo; y en la protección de las tropas del general Whittingham, que cubrían la carrera de Madrid. Es interesante esta participación inglesa: Wellington reconocerá después que su gestión personal se había limitado a aconsejar a dos Capitanes generales que no se opusiesen a la acción de Elío. También Whittingham tenía experiencia americana, pues había participado en las invasiones inglesas del Rio de la Plata, que las milicias criólas supieron repeler. 
En los seis mal llamados años o primer período absolutista, 1814-1820, el desgobierno fue la norma, los escándalos de la camarilla y del propio rey casi cotidianos, la guerra de América una realidad dolorosa. La sociedad española necesitaba un cambio, sentimiento difuso que podía ser perfectamente canalizado por los liberales. Pero sobre todo el ejército aparecía como una palanca formidable de cambio: en el Antiguo Régimen el ejército tenía lógicamente estructura señorial, aunque en sus filas aparecen ya en los escalones medios y algunos incluso en el generalato oficiales de gran significación cultural: poetas, traductores, ingenieros, el ejército empezaba a ser ya en las postrimerías del Antiguo Régimen una rama de la administración del Estado que proporcionaba los medios para el ejercicio de los talentos - aunque abundase también el otro tipo de oficial inculto y tosco. La Guerra de la Independencia va a cambiar profundamente a este Ejército, al entrar en él procedentes de las guerrillas, o por nombramiento de las Juntas, oficiales salidos de la sociedad civil de carácter mesocrático - labradores, estudiantes, médicos, etc. En 1814 la política de congelar los ascensos de estos oficiales, para favorecer a los de origen aristocrático, provoca naturalmente el descontento de los preteridos. El Ejército adquiere así una gran sensibilidad para propiciar el cambio, ya que ha sido el primer engranaje de la administración del Estado en haberlo experimentado. De 1814 a 1820 asistimos a una insurrección por año, casi todas de carácter militar con apoyo civil, y en 1820 por fin al triunfo de la revolución.

Es importante observar que el ejército que en 1820 se pronuncia proclamando la Constitución, no reclama nunca el poder para sí mismo, sino que se moviliza al servicio de la sociedad civil. Entre los militares de este momento, el más destacado, Rafael del Riego, por su desprendimiento y bondad y sincera creencia en la Constitución llega a convertirse en un héroe popular, como no ha habido otro en toda la historia de España. El ejército se limita a restablecer la Constitución, pero mientras se forma el primer gobierno una Junta provisional, en Madrid, que nadie sabe cómo ha sido nombrada pero que está presidida por el arzobispo de Toledo, primo del Rey, toma las medidas necesarias para que la nueva vigencia teórica de la Constitución no se transforme en revolución popular.

La historia del Trienio liberal se traduce en un extraordinario avance legislativo, pero a la vez en una gran timidez en lo social. Desaparece de nuevo la Inquisición, pero no el diezmo completo. Tampoco las Cortes encaran con valentía el problema americano, a pesar de propuestas de los diputados americanos de su seno que hoy nos hubiesen parecido muy 


\section{Varia}

halagüeñas, aunque probablemente tardías: tres Estados, con capital en Mexico, Lima y Santa Fe, con Parlamentos y gobiernos absolutamente independientes, y solamente con Marina común con España y comercio libre, sin pago de ningún gravamen. En materia de Hacienda, las Cortes no estuvieron tampoco a la altura que se esperaba de ellas: ni por un momento comprendieron la inmensa necesidad que tenía el pueblo de ser aliviado de la carga impositiva - solamente lo comprendió algún diputado aislado, como Juan Romero Alpuente, cabeza de la minoría exaltada. Y para llevar adelante la modernización - burguesa - del Estado, las Cortes y los gobiernos sucesivos prefirieron aliarse con las antiguas clases feudales y con la burocracia, condenando los intensos movimientos urbanos de 1821. No se rechaza la alianza incluso con la Iglesia, pero justo es indicar que la desamortización se antepone a cualquier otra consideración. La desamortización es necesaria para pagar la inmensa Deuda pública que tiene acumulada el país, y la propia transformación burguesa que se está buscando.

Así al pueblo, del que se desconfía, se le da siempre un valor subordinado, y aunque se le predican las excelencias del sistema, en la práctica el pueblo, que no vive de abstracciones, no las ve.

El hecho de que Fernando VII haya jurado la Constitución de Cádiz le enajena las simpatías del sector absolutista más intransigente, que ya en 1821 anda pensando en otro príncipe menos contaminado. Esto no quiere decir que Fernando VII sea un auténtico rey constitucional: conspira contra el sistema, y mantiene una espécie de gobierno en la sombra. La ausencia de una enérgica política agraria de los liberales levanta contra ellos las primeras guerrillas absolutistas, ya a finales de 1820, con bastante participación eclesiástica. La evolución de los acontecimientos lleva a los absolutistas a intentar la contrarrevolución en grande en Julio de 1822: ante su derrota a manos del pueblo urbano, no cabe ya más que la intervención de la Santa Alianza. Un ejército francés, al mando del Duque de Angulema, entra en España en Abril de 1823, convirtiendo la invasión casi en un paseo militar: el pueblo por lo general no se defiende, tampoco lo hace el gobierno ni las Cortes que huyen hacia el sur, antes incluso de que los primeros soldados franceses pasen la frontera. Los militares abandonam uno tras otro, excepto unos pocos - Riego, El Empecinado - de conducta admirable, aunque no logran evitar la catástrofe.

La explicación del desastre de 1823 radica naturalmente en que el pueblo no ha sentido la necesidad de defender al régimen, y esto no sólo por influjo eclesiástico, sino por lo ya apuntado antes de que el liberalismo no ha sabido ayudarle 
prácticamente en nada - salvo a una franja exigua del pueblo urbano. Pero además parece haber habido un auténtico crimen político, fruto de un cálculo errado: frente a los exaltados, gorros y comuneros, los moderados, anilleros y demás oligarcas que detentan el poder han pensado que la invasión francesa podrá ser beneficiosa, al librarles de la presión popular, y cambiar el régimen español en algo muy parecido al de la Carta francesa; pero no contaban con la violencia de la reacción española, ante la cual los franceses invasores serían los primeros sorprendidos.

En Octubre de 1823 vuelve España al absolutismo, pero aunque el nuevo régimen se parece al de 1814, pronto encuentra la burguesía la manera de colaborar con él; y aunque habrá continuas insurrecciones y conjuraciones, esta vez se trata de fenómenos de doble naturaleza: liberal, desde el interior y desde el exilio; y absolutista ultramontano, que busca el restablecimiento de la Inquisición - Fernando VII no se ha atrevido a hacerlo - y la conversión de España en una teocracia. Muy pronto de este movimiento saldrá el carlismo.

El segundo período absolutista sorprende por su carácter sangriento, a que le obliga su propia condición y la serie continua de conspiraciones liberales. Desagravios al Santísimo Sacramento, expedientes de purificación, persecuciones en virtud de las excepciones a la amnistía de 1824, comisiones militares, métodos policiales del tristemente célebre Calomarde, policías paralelas, que se vigilan las unas a las otras; y voluntarios realistas, que se dedican a amedrentar y apalear a los ciudadanos, a destruir y ensuciar los símbolos liberales. Falta un libro sobre estos voluntarios, que parecen la utilización por el absolutismo de un instinto de venganza de clase, ya que muchos liberales significados habían pertenecido a las clases económicamente holgadas. La represión eclesiástica — Tribunales de la Fe, de carácter diocesano - completa el panorama. Pelo aunque esto sea espantoso, hay que advertir que muchos exaltados fueron perseguidos, a veces hasta la muerte, en 1823 por los moderados, ya que el odio entre los dos sectores del liberalismo llegaba a proporciones trágicas.

No obstante la falta total de libertad y el ahogo ideológico del régimen, la burguesía encuentra la manera de colaborar con él - es decir, de buscar su propio medro - a través de la Junta de Fomento de la Riqueza del Reino, creada en 1824, de la Ley de Minería - promulgada en 1825, por supuesto en sentido individualista - y de la promulgación del primer Código de Comercio en 1829.

Fernando VII se había casado tres veces y no había tenido descendencia. Era lógico pensar que el sector oscurantista del 


\section{Varia}

país esperaba que a su muerte la corona pasaría a las sienes de Don Carlos María Isidro, príncipe que gozaba de todas sus simpatías. Pero Fernando VII se casó por cuarta vez, con María Cristina, de la rama borbónica de Nápoles, con la que tuvo dos hijas, Isabel y Luisa Fernanda, la primera nacida en 1830. Desde Felipe $\mathrm{V}$, el primer Borbón, regía en España la llamada Ley Sálica, que excluye a las mujers de la sucesión al trono. Carlos IV hizo derogar esta ley en las Cortes de 1789, pero como tenía hijos varones o por otras razones no publicó la ley, con lo cual quedaba vigente la anterior. Al nacerle una hija, Fernando se apresuró a publicar la derogación de la Ley Sálica, a fin de asegurar la corona en las sienes de su hija. Carlos alegó que, habiendo nacido en 1788, no le afectaban los términos de la derogación, es decir que seguía siendo el único heredero del trono.

Así, como una cuestión dinástica, comenzó el problema carlista - del nombre del Pretendiente - en España. La muerte del rey en 1833 precipitó las cosas. Por una parte fue proclamada reina Isabel II, bajo la regencia de su madre María Cristina. Por otra parte, Carlos desde Portugal — en donde se había refugiado ya en vida de su hermano - reclamó también la corona. La cuestión se iba a dirimir por las armas, en una larga guerra civil, hasta 1839 en el sector vasco-navarro y 1840 en el catalano-aragonés. Es importante subrayar desde el principio la geografía del carlismo para poder entender su naturaleza. Aunque en 1833 había carlistas por toda España, rápidamente se vio que el movimiento arraigaba en los antiguos países de fuero, en los que el carlismo implicaba una posición for alista, frente al centralismo de los liberales; y se transformaba al mismo tiempo en un movimiento campesino, en defensa de las instituciones precapitalistas, amenazadas por el sentido de la propiedad liberal, propiedad quiritaria e individualista, que pensaba en la desamortización eclesiástica, como vía de pagar la Deuda y sufragar los gastos de la construcción del Estado. La Iglesia, o su sector más reaccionario tanto en España como en Roma, no necesitaba de este estímulo para «colonizar» al carlismo, dándole así el aspecto típico de defensor de la fe. De esta forma el carlismo cobró fuerza en la zona vascongado-navarra, en Cataluña y con menos intensidad en Aragón.

No es éste el momento de contar los sucesos de la primera guerra carlista. Bastará decir que la guerra duró demasiado, acaso porque algunos militares del bando cristino esperaban que la guerra les diese el poder. Este fue probablemente el caso de Luis Fernández de Córdova, general a quien sus partidarios llamaban «El joven Caudillo». Aquí habría que descender a la biografía individual para que viésemos cómo el 


\section{Absolutismo y Liberalismo}

absolutismo del pasado empieza a ser compatible con el liberalismo oficial: Luis Fernández de Córdova militó en Julio de 1822 en las filas realistas; ahora en 1833, no es carlista, como nos parecería lógico, sino isabelino.

Pero al mismo tiempo que la guerra significaba el ascenso político de los militares, el peligro carlista es el responsable de ios cambios políticos ocurridos en el país cristino. María Cristina en 1833 tuvo por fuerza que abrazar el bando liberal, ya que Don Carlos encabezaba el absolutista. Pero el liberalismo de María Cristina no iba muy lejos: por educación y por familia era tan absolutista como su difunto marido. Lo primero de todo era salvar la corona de su hija. Comenzó con un gabinete Cea Bermúdez, que quiso ser una especie de despotismo ilustrado fuera de su marco, que no contentó a nadie. En 1834 llegó al poder Martínez de la Rosa, el dramaturgo, el malfamado político del Trienio Liberal. Martínez de la Rosa creyó que el problema constitucional de España se solucionaba en el sentido que había marcado la reacción interior en el Trienio: es decir con dos Cámaras, que asegurasen con su mera existencia que la revolución no llegaría a mayores. Además, en lugar de Constitución una Carta otorgada llamada pomposamente Estatuto Real, mientras que las cámaras se llamaban Estamento de proceres y Estamento de procuradores. Merece que nos fijemos en este lenguaje: la palabra Estamento recordaba el Antiguo Régimen, y la palabra procuradores también, pero enlazando a la vez con las Cortes medievales (en España volverá a haber procuradores, y no diputados, en las Cortes franquistas). Al Estamento de proceres se pertenecía por derecho propio o por nombramiento, nunca por elección. Sólo era electiva la segunda cámara, pero para poder elegir y ser elegido se requería la posesión de cuantiosos bienes de fortuna. El Estatuto era por tanto un sistema censitário, que trataba de imponer una sociedad oligárquica.

Tampoco el Estatuto contentó a nadie, pero en los dos años en que rigió ocurrieron sucesos de la máxima importancia. En 1834 mismo tuvo lugar la matanza de frailes de Madrid, causada por el miedo al carlismo en momentos de enajenación colectiva - una epidemia de cólera. En los meses siguientes la matanza de frailes se va a repetir en varias ciudades de España, lo que contribuirá a sua desaparición - a este fenómenos contribuirán también las tendencias secularizadoras del primer cuarto del siglo, la calamitosa economía conventual - con levísimas excepciones - y la guerra de la independencia y las discordias civiles. El resultado será preparar el terreno a la desamortización de 1836, obra de Mendizábal, quien no hizo a este respecto más que dar estado legal a una situación de hecho. 


\section{Varia}

El miedo al carlismo, más la necesidad de completar o acabar la revolución burguesa, explica también los acontecimientos revolucionarios de 1835 y 1836 . Movimientos de desobediencia cívica, que recuerdan a los de 1821, tienen lugar en 1835 en varias ciudades, mezclados con problemas de subsistencias y de varia índole, en Madrid, Huesca, Málaga, Murcia, Reus, Zaragoza - en ambas ciudades con asesinato de frailes - y en Barcelona, en donde la asonada cobra caracteres ludditas con la quema de la fábrica de El Vapor, lo que asustará a la burguesía. El gobierno declara el estado de excepción, pero entre Agosto y Septiembre el movimiento se extiende a Cádiz y quince ciudades más, razón por la cual la reina tuvo que llamar a formar gobierno a Mendizábal. Los andaluces habían formado una Junta Central de Andalucía, con un ejército que amenazaba a Madrid, pero la intervención de la Junta de Barcelona, interclasista, desvió este ejército de su finalidad revolucionaria, destinándolo a combatir al carlismo en la zona aragoneso-catalana. Tenemos aquí una de las más claras actuaciones no revolucionarias, mejor antirrevolucionarias, de la burguesía, en este caso la catalana.

En 1836 se repite el proceso, que culmina con la famosa actuación de los sargentos en el Real Sitio de La Granja, y en consecuencia el restablecimiento de la Constitución de 1812, y la convocatoria de Cortes Constituyentes. El resultado de las nuevas elecciones dio un Parlamento mayoritariamente progresista, pero los diputados sacrificando sus ideales en aras de un entendimiento con los moderados - al fondo una vez más la amenaza carlista - elaboraron una Constitución moderada, que recorta los derechos del pueblo y agranda los del poder ejecutivo. Conclusión paradójica: las revoluciones de 1835 y 1836 han engendrado las Cortes Constituyentes, y éstas la Constitución de 1837, pero ésta poco tiene que ver con la satisfación de los deseos del pueblo, origen de todo el proceso.

Eliminado el pueblo políticamente hablando, sólo queda el ejército. El general que lo mande y lo lleve a la victoria en la guerra civil será, de hecho, el árbitro de España. Por una serie de circunstancias favorables este puesto le corresponde al general Baldomero Espartero, quien no tiene historia en los pasados disturbios civiles puesto que ha hecho prácticamente toda su carrera en América - a sus partidarios se llamará «los ayacuchos». Espartero se inclina por el partido progresista. Narváez y Luis Fernández de Córdova intentan en 1838 arrebatarle el botín, mediante la organización de un supuesto ejército de reserva a que se entrega el primero. Pero su intento fracasa, y los dos tienen que pasar al exilio. 


\section{Absolutismo y Liberalismo}

Ahora la pugna va a ser con la propia reina. Triunfante Espartero en 1839, María Cristina intenta atraerlo a su partido, sin conseguirlo. Espartero se ha llenado de fama y de gloria cuando en los campos de Vergara se da el famoso Abrazo con el general carlista Maroto, por el que termina la guerra en la región vasco-navarra (en 1840 terminará en la catalana). La alegría del país es sincera, y se alaba la generosidad de los términos del acuerdo: paz y fueros, sí, pero también una cláusula en virtud de la cual todos los oficiales carlistas pasan, con igual graduación, al ejército liberal.

María Cristina en 1840 decide llevar adelante la llamada Ley de Ayuntamientos, en abierta violación de la Constitución de 1837. Con su augusta hija se traslada a Barcelona, donde está Espartero, con la idea todavía de ganarlo, o de crear las condiciones que le obliguen a desenvainar su espada al servicio del trono, y en contra de los intereses populares. Espartero evita todo compromiso, María Cristina persiste en la Ley de Ayuntamientos y se marcha a Valencia. La revolución de Septiembre de 1840, que estalla en Madrid y en otros puntos, la obliga a abandonar la Regencia y marcharse de España. El «espíritu de Septiembre» hace felices a los liberales, mientras su odiada ex-reina lanza desde Marsella un Manifiesto, que significa el primer asalto al nuevo régimen.

Contra él están los moderados, los exiliados — Narváez, María Cristina - y Francia. El partido progresista, aparentemente triunfador, pronto se va a dividir. Hay que nombrar Regente del reino, y los progresistas se dividen rápidamente en partidarios de la Regencia única (Espartero) o de la Regencia trina. Esta división, que el tiempo va a ahondar, les es fatal. Vence la Regencia única, y Espartero pasa a ocupar la más alta magistratura del país. Políticamente inexperto o indeciso, Espartero sin embargo durante la guerra civil había dado pruebas de tener mano dura en materia de disciplina militar. En 1841 estalla una sublevación moderado-absolutista contra él: Montes de Oca en el País Vasco - quien trata de atraerse a los antiguos carlistas - Leopoldo O'Donnell en Pamplona - quien no vacilará en bombardear la ciudad - Diego de León en Madrid. Derrotados, Montes de Oca y Diego de León son pasados por las armas. El último sabe morir gallardamente, ganándose como un nuevo Don Rodrigo Calderón las simpatías populares. Espartero ha ganado la prueba, pero el número de sus enemigos ha aumentado y se ha precisado mejor.

En 1841, lo mismo que en 1840, Barcelona es fundamentalmente una ciudad esparterista, aunque los moderados, allí como en todas partes, sean sus enemigos. Pero los contactos diplomáticos y comerciales con Inglaterra van a cambiar la 
situación. Se acusa a Espartero de haber caído en un librecambismo absoluto, que producirá la ruina de la industria catalana y por tanto el hambre en los hogares populares. La burguesía mueve los hilos, tocando las fibras sensibles del pueblo. El resultado es la sublevación barcelonesa de 1842, frente a la cual Espartero no supo evitar el bombardeo de la ciudad, con la consiguiente pérdida inevitable de prestigio. En Barcelona apareció un movimiento republicano, con infantilismos de diluvio universal, que ha preocupado a los historiadores. De su autenticidad parece no caber duda: de su inoportunidad, vistos los resultados, tampoco. En una perspectiva nacional española este grave conflicto habrá que atribuirlo, en espera de nuevas investigaciones, a la diferencia de desarrollo económico y social entre las diversas regiones de España.

Las impertinencias frente al mismo Regente del Ministerio formado, ya en 1843, por Joaquín María López, y la negativa de Espartero a aceptar sus exigencias, generalizaron el movimiento insurreccional, que estalló como un reguero de pólvora en Málaga, Reus, Barcelona, Valencia, Alicante, Cartagena, Murcia, San Roque, Sevilla, Coruña, Badajoz, Santander, País Vasco, Navarra, Cuenca, Valladolid y Burgos. En su origen muchos de estos movimientos no iban contra Espartero, pero los moderados sabían lo que hacían. La mayoría de estas insurrecciones estaba compuesta por moderados y progresistas, aliados, y su finalidad confesada era el estricto cumplimiento de la Constitución. En Valencia actuaba Don Pedro Sabater, hombre al que podemos calificar de absolutista. Valencia abrió sus puertas a los emigrados, y dio a Narváez el mando de las tropas. Esto, y la extraña indecisión política de Espartero en el momento supremo, dieron al traste con su Regencia. Todavía los progresistas formaron gobierno, pero el amo de la situación era Narváez, mientras las Cortes procedían ilegalmente a proclamar mayor de edad a Isabel II, a sus trece años.

Una intriga palaciega quitó de en medio a los progresistas, sumiendo a España en la atroz dictadura de los moderados. Entonces se vio a los antiguos voluntarios realistas ingresar casi en bloque en la policía, mientras los oficiales de tendencias exaltadas eran perseguidos y en gran número expulsados del ejército. A partir de aquel momento los sublevados de 1843 se dedicaron a fusilar inmisericordes a sus contrarios: se vio esto en la sublevación de Alicante y Cartagena, en la de la Rioja (Zurbano) y Aragón, en las partidas republicanas andaluzas, en la revolución gallega de 1846, en la llamada conjuración carlo-republicana de Cataluña, en los ecos españoles de 1848 - Madrid, Huesca, Barcelona. En muchas de estas agitaciones, la parte militar está asegurada por ex-oficiales 


\section{Absolutismo y Liberalismo}

expulsados del ejército a partir de 1843 por sus opiniones liberales. No habrá en España revolución de 1848, porque Narváez y el ejército lo impiden; pero a estas alturas el régimen se ha vuelto sangriento, todavía más que el absolutista de 1814-1820 y 1823-1833, que es al que se parece.

No obstante este régimen no intenta volver a la situación anterior a 1808. Le falta la bendición eclesiástica. El Concordato de 1851 , se la va a dar: al renunciar la Iglesia a sus antiguas propiedades desamortizadas, $\mathrm{y}$ al adquirir plena capacidad jurídica civil, los católicos pueden volver a integrarse en el sistema. La conversión del liberalismo en absolutismo, pero que gobierna a través de un Parlamento y con una Constitución puramente formales, está asegurado. Ejército e Iglesia, más Guardia Civil desde 1844, serán los puntales del nuevo orden.

Habrá todavía revoluciones, como la de 1854-56, originada en la disputa por el botín entre los oligarcas; y la de 1868-1874, que acabó con Isabel II y dio ocasión a la aparición otra vez de las masas populares. Pero se impuso el orden, y a pesar del crecimiento interior de España, la ficción continuó pese al 98 hasta 1923. La historia posterior es bien conocida, y se sale de mis propósitos de hoy. Sólo diré que para mí estudiar el siglo XIX es la única preparación posible para entender el XX. 